\title{
Rview of phytoremediation of soil contaminated by vanadium
}

\author{
Zhen zhong $\mathrm{Wu}^{1,2^{*}}$, Jin yanYang ${ }^{2}$, You xian $\mathrm{Zhang}^{1}$, Zong qian $\mathrm{Jia}^{1}$ \\ ${ }^{1}$ College of Earth and Environmental Sciences, Lanzhou University, Lanzhou 730000, Gansu, China \\ ${ }^{2}$ College of Architecture and Environment, Sichuan University, Chengdu 610065, Sichuan, China
}

\begin{abstract}
Vanadium is a nontrivial multi-valent metallic element, which has been increasingly used in modern society. The widespread application of vanadium promotes the rapid and sound development of the economy and society, simultaneously brings out increasingly prominent environmental problems, e.g., soil vanadium pollution. Therefore, the remediation problem of vanadium-contaminated soil has been received growing attention. Phytoremediation has become a significant constituent in vanadium-contaminated soil remediation attributable to its veritable merits such as cleanness, esthetics, cost-effectiveness, convenience, and sustainability. Phytoremediation is mainly dependent on hyperaccumulator plants, even though the actuality that the vast majority of hyperaccumulator plants are characterized by low biomass yield and slow-growing. Consequently, the intensity in screening the undiscovered hyperaccumulators should be strengthened. Meanwhile, it is imperative to further explore the vanadium accumulation and translocation characteristics of some non-hyperaccumulative but tolerant plants with moderate biomass to remediate the soil contaminated with vanadium. Taken together, further comprehensive researches of tolerance mechanisms of remedial plants against vanadium are quite necessary to decontaminate soils contaminated by vanadium efficiently.
\end{abstract}

\section{Introduction}

Vanadium, a gray metallic element (atomic number of 23) of centered cubic lattice ${ }^{[1]}$, has been extensively utilized in multi-fields involving the iron and steel industry, pharmaceutical engineering, aviation, ceramics, and nuclear technology ${ }^{[2]}$. The release rate of global man-derived vanadium into the environment (soil and water) is accelerating, and consequently, vanadium is again concentrating in the environment ${ }^{[3]}$. Survey indicated that global vanadium production, mainly from mining, had more than doubled amongst the past two decades ${ }^{[4]}$. Vanadium has been reviewed as a potentially detrimental pollutant parallel to mercury, lead, and $\operatorname{arsenic}^{[5-7]}$. High quantities of vanadium are noxious to both plants and animals and occasionally it endangers human health ${ }^{[8]}$. Ingestion of high amounts of vanadium can lead to severe diseases incorporating renal damage and possible pulmonary tumors ${ }^{[8,9]}$. Recently, human-derived influx, including the burning of fossil fuel, mining, iron-steel smelting, and dying, leads to excessive vanadium into the environment, which causes the vanadium pollution of soil ${ }^{[3,10]}$. The environmental pollution resulting from vanadium has become a concern worldwide and a significant problem involving environmental protection and economic benefits ${ }^{[11,12]}$. In view of the potential environmental and health problems caused by the increased amassing of vanadium in the environment, it is urgent to remediate the vanadium-contaminated environment.

\section{Phytoremediation of soil contaminated by vanadium}

Phytoremediation, a solar energy-driven clean-up technology, has gained increasing attention in the current harmonious, friendly, and sustainable development of human society. The remediation of vanadium-contaminated soil mainly includes physical-chemical and biological methods ${ }^{[13]}$. As a commonly used bioremediation method, phytoremediation is an appealing technology for discarding vanadium from the soil due to its cost-effectiveness, ease to monitor, eco-friendly, and application on a large-scale ${ }^{[14]}$. By far, the phytoremediation of soil contaminated by vanadium mainly consists of phytoextraction and phytostabilization [14].

Phytoextraction is mainly realized by employing hyperaccumulators who can absorb vanadium from contaminated soil and subsequently transferred the vanadium entered the plant root to aerial parts, and finally reap the aboveground portions and retrieve the metal. Few vanadium (potential) hyperaccumulators have been screened out due to the poor vanadium transfer capability of the plant from its root to aboveground parts. Some potential vanadium hyperaccumulators, e.g.,

*Corresponding author: wuzhzh16@1zu.edu.cn 
Setaria viridis ${ }^{[15]}$, Phaseolus vulgaris L. ${ }^{[16]}$, Thuja ${ }^{[17]}$, and Zea mays $\mathrm{L}^{[18]}$, etc., have been identified for their relatively strong resistance against vanadium stress and high vanadium accumulation in their bodies. In terms of phytostabilization, plants root can uptake and store large quantities of vanadium, though the low vanadium translocation capability from its roots to aerial organs. Plant immobilization prevents the entrance of vanadium to the food chain through the plant to a certain extent even though the metal was not eliminated from the contaminated soil matrice. To a larger extent, phytostabilization aims at declining the bioavailability of vanadium and restraining its off-site transport ${ }^{[19]}$. Revegetation of soils in-, adjoin- or away from mining areas contaminated by vanadium not only limits the diffusion of vanadium in the environment but also can clean up the soil by way of reaping aboveground parts of the plant, simultaneously improves the soil properties.

\section{Effect of vanadium on plnat growth}

Vanadium is essential to the growth of some algae (e.g., green alga ${ }^{[20]}$. However, the essentiality of vanadium for higher plant growth has not yet been conclusively demonstrated. Trace quantities of vanadium (e.g., soil vanadium $<2 \mathrm{mg} \mathrm{kg}^{-1}$ ) have shown the stimulative action in chlorophyll synthesis, nutrient intake, nitrogen assimilation, potassium usage of the plant ${ }^{[13]}$. High levels of vanadium (usually, $>2 \mathrm{mg} \mathrm{kg}^{-1}$ ), however, lead to dwarfing, chlorosis, necrosis, membrane damage, cell death, growth retardation, root deformation, and reduced biomass ${ }^{[16,21,22]}$. Higher concentrations of vanadium not only negatively affected seed germination and subsequent seedling growth but also influence the reproductive growth of plants ${ }^{[23,24]}$.

\section{Screening of remediation plants}

The pivotal capabilities of hyperaccumulators mainly include: (1) relatively high metal concentration levels in aerial tissues when grown in their natural habitat, generally, $10000 \mathrm{mg} \mathrm{kg}^{-1}$ for $\mathrm{Zn}$ and $\mathrm{Mn}, 1000 \mathrm{mg} \mathrm{kg}^{-1}$ for $\mathrm{Co}, \mathrm{Ni}, \mathrm{Cu}, \mathrm{Se}, \mathrm{As}$, and $100 \mathrm{mg} \mathrm{kg}^{-1}$ for Cd; (2) metal transfer coefficient (TF) (the ratio of metal concentration in plant shoot to that of in root) should be $>1$; (3) metal bioconcentration coefficient (BF) (the ratio of metal concentration in the plant to that of in growth substrate $)^{[18]}$ should be $>1$. In general, TF and BF are two critical parameters in the choice of vanadium hyperaccumulators. Besides, desirable plants that can be used in phytoremediation are generally inherited with several merits like the deep root, fast growth, and high biomass yield. Indeed, few remediators are equipped with all of these merits. It is necessary to be flexible in selecting the actual remediation plants, e.g., plants with strong vanadium resistance and rapid growth may be chosen for the candidates even though the low biomass yield.

\section{Plant vanadium tolerance mechanism}

Vanadium is concentrated primarily in almost all plants' $\operatorname{roots}^{[13,25,26]}$. Moreover, vanadium is considered to precipitate as $\mathrm{CaVO}_{3}$ in plant roots, and the storage manner of vanadium is presumed to be the critical tolerance mechanism of plants against vanadium toxicity ${ }^{[24]}$. From the viewpoint of subcellular level, vanadium entered the plant cell was mainly bound with the components of the cell wall consist of proteins, cellulose (hemicellulose), lignin, and ligands (e.g., oxhydryl, amidogen, and carboxyl $)^{[13]}$. Alkali-soluble pectin constitutes the significant vanadium binding site in the cell wall ${ }^{[27]}$. The bio-reduction of $\mathrm{V}(\mathrm{V})$ to $\mathrm{V}(\mathrm{VI})$ during plant vanadium uptake is also deemed as a critical vanadium-tolerance mechanism ${ }^{[28,29]}$. Vacuoles compartmentalization of vanadium in roots and stems was in part responsible for the lower vanadium accumulation in aboveground parts of plants ${ }^{[13]}$. In addition, to cope with the elevated vanadium challenge, plants will regulate and enhance the production of some metabolites (e.g., lignin, tannins, and flavonoid) to counteract vanadium ${ }^{[30]}$.

\section{Microbial-assisted phytoremediation}

Vanadate is a known electron acceptor in the anaerobic respiration of microorganisms ${ }^{[31]}$. Some researches related to microorganism-assisted bioremediation have been conducted in recent years. High toxicity vanadium $\mathrm{V}(\mathrm{V})$ can be reduced to less toxicity vanadium $\mathrm{V}(\mathrm{VI})$ via microorganisms, for that vanadium is a redox-sensitive metal ${ }^{[13]}$. For example, Geobacter metallireducens and Shewanella oneidensis can grow in the medium of vanadium which acts as the sole electron acceptor ${ }^{[32]}$. Screening new and valuable endophytic bacteria is feasible to enhance the efficiency of phytoremediation ${ }^{[33]}$. Inoculation of some vanadium-resistance endophytes (e.g., bacteria and fungi) to remediation plants not only facilitates the host plant growth but also promotes plant vanadium accumulation by way of microbial detoxification.

\section{Conclusion and re-optimization}

Phytoremediation of vanadium-contaminated soil has made relatively good achievements in theoretical research, and the fundamental research is constantly deepening. It is pretty necessary further to strengthen the screening of (potential) vanadium hyperaccumulators. Simultaneously, proper readjustment in choosing remedial plants is required to make phytoremediation play a greater benefit in reality application. It seems to be more suitable to choose some adversity-resistant plants with moderate biomass yield while can be harvested several times annually. Meanwhile, it is more feasible to fermentate green harvested fresh aboveground parts to produce biogas and bioethanol, etc., before metal retrieval. Considering that remediation plants growing in mining areas are confronted with various abiotic stress factors, moderate application of plant growth regulators 
(e.g., auxins, gibberellins, brassinosteroids, cytokinins, jasmonate, salicylic acid) will be beneficial to promote the plant better and faster growth. Microbial-assisted phytoremediation presented great potential in laboratory researches, but its auxiliary efficacy in actual remediation of vanadium-contaminated soils in mining areas needs to be further verified. On the other side, soil contaminated with vanadium in mining areas is commonly mixed with large quantities of crushed stones. Therefore the soil and fine stones can be collected together by separating the larger pieces of crushed stones, thus forming a simple contaminated soil remediation area on the site, which is more conducive to in-situ phytoremediation of soil contaminated by vanadium. Finally, it is necessary to dissect plant vanadium tolerance mechanism from plant physiology, biochemistry, metabolism, and gene in a more comprehensive way to enhance phytoremediation efficiency.

\section{Acknowledgment}

This work was financially supported by the Chengdu Science and Technology Project [2018-YF05-00760-SN], and the Strategic Cooperation Project Between Sichuan University and Panzhihua Municipal Government.

\section{Reference}

1. E. Del Carpio, L. Hernández, C. Ciangherotti, V. Villalobos Coa, L. Jiménez, V. Lubes, G. Lubes, Coord. Chem. Rev. 372 (2018)

2. B.G. Zhang, Y.N. Li, Y.M. Fei, Y.T. Cheng, Environ. Sci. Technol. 55 (2021)

3. J.A.J. Watt, I.T. Burke, R.A. Edwards, H.M. Malcolm, W.M. Mayes, J.P. Olszewska, G. Pan, M.C. Graham, K.V. Heal, N.L. Rose, S.D. Turner, B.M. Spears, 2018. Environ. Sci. Technol. 52 (2018)

4. W.H. Schlesinger, E.M. Klein, A. Vengosh, Proc. Natl. Acad. Sci. U. S. A. 114 (2017)

5. J.Y. Yang, Y. Tang, K. Yang, A.A. Rouff, E.J. Elzinga, J.H. Huang, J. Hazard. Mater. 264 (2014)

6. J. Yang, Y.G. Teng, J. Wu, H.Y. Chen, G.Q. Wang, L.T. Song, W.F. Yue, R. Zuo, Y.Z. Zhai, Chemosphere 171 (2017a)

7. Y.Q. Yu, J.Y. Yang, Chemosphere 215 (2019)

8. S. Wang, B.G. Zhang, T.T. Li, Z.Y. Li, J. Fu, Environ. Int. 138 (2020)

9. G.D. Chen, H.Z. Liu, Environ. Sci. Technol. 51 (2017)

10. M. Imtiaz, M.S. Rizwan, S.L. Xiong, H.L. Li, M. Ashraf, S.M. Shahzad, M. Shahzad, M. Rizwan, S.X. Tu, Environ. Int. 80 (2015)

11. J.H. Huang, F. Huang, L. Evans, S. Glasauer, Chem.
Geol. 417 (2015)

12. S.M. Shaheen, J. Rinklebe, Appl. Geochem. 88 (2018)

13. A. Aihemaiti, Y.C. Gao, Y. Meng, X.J. Chen, J.W. Liu, H.L. Xiang, Y.W. Xu, J.G. Jiang, Sci. Total Environ. 712 (2020)

14. L. Chen, J.R. Liu, W.F. Hu, J. Gao, J.Y. Yang, J. Hazard. Mater. 405 (2020)

15. A. Aihemaiti, J.G. Jiang, D.A. Li, T.R. Li, W.J. Zhang, X.T. Ding, Environ. Sci. Pollut. Res. 24 (2017)

16. D. Saco, S. Martín, P. San Jose, Biol. Plant. 57 (2013)

17. S.O. Akkus, B. Yaman, M. Yaman, J. Elem. 22 (2017)

18. E.G. Ameh, O.D. Omatola, S.B. Akinde, Environ. Earth Sci. 78 (2019)

19. V. Shah, A. Daverey, Environ. Tech. Innov. 18 (2020)

20. D.I. Arnon, G. Wessel, Nature 172 (1953)

21. A. Aihemaiti, J.G. Jiang, Y.C. Gao, Y. Meng, Q. Zou, M. Yang, Y.W. Xu, S.Y. Han, W.W. Yan, T. Tuerhong, J. Environ. Manag. 237 (2019)

22. M. Imtiaz, M. Ashraf, M.S. Rizwan, M.A. Nawaz, M. Rizwan, S. Mehmood, B. Yousaf, Y. Yuan, A. Ditta, M.A. Mumtaz, M. Ali, S. Mahmood, S.X. $\mathrm{Tu}$, Ecotoxicol. Environ. Saf. 158 (2018)

23. Z.Z. Wu, Y.X. Zhang, J.Y. Yang, Y. Zhou, C.Q. Wang, J. Plant Growth Regul. (2020)

24. J.Y. Yang, M. Wang, Y. Jia, M. Gou, J. Zeyer, Environ. Pollut. 231 (2017b)

25. J. Yang, Y.G. Teng, J.S. Wang, J. Li, Biol. Trace Elem. Res. 142 (2011)

26. Z.Z. Wu, J.Y. Yang, Y.X. Zhang, C.Q. Wang, S.S. Guo, Y.Q. Yu, Ecotoxicol. Environ. Saf. 207 (2021)

27. M. Hou, Y. Huo, X.H. Yang, Z.C. He, Plant Physiol. Biochem. 149 (2020)

28. B.G. Morrell, N.W. Lepp, D.A. Phipps, Environ. Geochem. Health. 8 (1986)

29. L.Y. Tian, J.Y. Yang, C. Alewell, J.H. Huang, Chemosphere 111 (2014)

30. M. Abedini, F. Mohammadian, South West. J. Hortic. Biol. Environ. 9 (2018)

31. W. Carpentier, L. De Smet, J. Van Beeumen, A. Brigé, J. Bacteriol. 187 (2005)

32. B.G. Zhang, L.T. Hao, C.X. Tian, S.H. Yuan, C.P. Feng, J.R. Ni, A.G. Borthwick, Bioresour. Technol. 192 (2015)

33. L. Wang, H. Lin, Y.B. Dong, Y.H. He, C.J. Liu, J. Hazard. Mater. 341 (2018) 